\title{
An extract from date seeds stimulates endogenous insulin secretion in streptozotocin-induced type I diabetic rats
}

\author{
Ahmed F. El Fouhil ${ }^{1}$, Aly M. Ahmed ${ }^{1}$, Muhammad Atteya ${ }^{1}$, Raeesa A. Mohamed ${ }^{1}$, \\ Amr S. Moustafa ${ }^{2}$ and Hasem H. Darwish ${ }^{1}$ \\ ${ }^{1}$ Department of Anatomy Faculty of Medicine, King Saud University, Riyadh, Saudi Arabia; \\ ${ }^{2}$ Clinical Biochemistry Unit, Department of Pathology, Faculty of Medicine, King Saud \\ University, Riyadh, Saudi Arabia
}

Corresponding author: Professor Ahmed Fathalla Ibrahim El Fouhil, Department of Anatomy, College of Medicine, King Saud University, PO Box 2925 (28), Riyadh, 11461, Saudi Arabia.

Submission date: April 23, 2013; Acceptance date: November 18, 2013; Publication date: November 23, 2013

\section{ABSTRACT}

Background: The efficacy of an extract from date seeds has been tested successfully on the glycemic control of type I diabetes mellitus in rats. A suggestion that date seed extract could stimulate certain cells to differentiate into insulin-secreting cells has been proposed. In order to investigate such a possibility, this study was conducted to measure C-peptide levels in the serum of type 1 diabetic rats treated with date seed extract.

Methods: Two hundred rats were divided into 4 groups. Group I served as the control. Group II was given daily ingestions of $10 \mathrm{ml}$ of date seed extract. Groups III and IV were made diabetic by streptozotocin injection and were given daily subcutaneous injections of $3 \mathrm{IU} /$ day of insulin for 8 weeks. Group IV received, in addition, daily ingestions of $10 \mathrm{ml}$ of seed extract. At the end of experiment, blood samples were collected from each rat, and blood glucose and serum Cpeptide levels were measured.

Results: No significant differences in the means of blood glucose and serum C-peptide levels were observed between groups I (control group) and II (date seed extract-treated control group). Group IV (date seed extract-insulin-treated diabetic group) showed a statistically significant reduction in the mean blood glucose level compared to Group III (insulin-treated diabetic group). The mean serum C-peptide level was significantly higher in group IV compared to group III.

Conclusion: Biochemical results suggested an increase in endogenous insulin secretion in the case of type 1 diabetic rats treated with date seed extract, which might be the cause of its hypoglycemic effect.

Keywords: Date seed extract; type 1 diabetes; serum C-peptide 


\section{BACKGROUND:}

Diabetes is a predominant public health concern affecting a large population in the whole world. The disease causes substantial morbidity, mortality, and long-term complications [1, 2]. Insulin is the only drug currently available to treat type 1 diabetes mellitus (T1DM), and its disadvantages have been discussed in previous studies [3, 4]. There is an increasing use of complementary and alternative medicine among general public [5]. In a previous study, we successfully tested the efficacy of an aqueous extract from date seeds on the glycemic control of T1DM in rats [6].

In another study, we demonstrated the safety of date seed extract administration on liver and kidneys of rats, and showed that a date seed extract-insulin combination minimizes the diabetic toxic effects on the liver and kidneys of rats, compared to insulin administration as a single drug [7]. However, the potential mechanism by which date seed extract exerts its hypoglycemic effect remains uninvestigated. A suggestion that such an extract could stimulate certain cells to differentiate into insulin-secreting cells has been proposed [6].

C-peptide (connecting peptide), a 31-amino-acid polypeptide, represents the midportion of the proinsulin molecule. During insulin secretion, it is enzymatically cleaved off and cosecreted in equimolar proportion with mature insulin molecules. Because synthetic insulin does not have such a peptide, the level of C-peptide can show how much insulin is being secreted in the body [8]. The present study aimed to investigate the mechanism by which an extract of date seeds exerts its hypoglycemic effect, through measurements of C-peptide levels in serum of type 1 diabetic rats treated with date seed extract.

\section{METHODS:}

Two hundred and fifty male adult Sprague Dawley albino rats weighing 250-300 g, obtained from the Animal House, Faculty of Medicine, King Saud University, Riyadh, Saudi Arabia, were used in this study. Principles of laboratory animal care were followed, as well as specific national laws were applicable. The study was first designed in 5 groups of 50 each. Rats in group $\mathrm{V}$ were diabetic taking daily ingestions of $10 \mathrm{ml}$ of seed extract. However, most of the animals of this group died in the first 2 weeks of experiment. Thus, we excluded all animals of group $\mathrm{V}$ from the study. Therefore, the remaining two hundred rats were divided into 4 groups of 50 each. Group I was used as a control group that did not take either insulin or date seed extract. Group II was used as a control group that was given a daily ingestion of $10 \mathrm{ml}$ of the date seed extract for 8 weeks [6]. Group III was treated with a daily subcutaneous injection of insulin. Group IV was treated with a daily subcutaneous injection of insulin immediately followed by a daily ingestion of $10 \mathrm{ml}$ of the date seed extract for 8 weeks. Diabetes mellitus was induced in groups III and IV by a single intravenous injection of freshly prepared streptozotocin (Sigma Chemical Co, St. Louis, Missouri, USA) at a dose of $60 \mathrm{mg} / \mathrm{kg}$ body weight dissolved in $0.1 \mathrm{~mol} / \mathrm{l}$ citrate buffer ( $\mathrm{pH}$ 4.5) [9]. Rats in groups I and II received an equivalent dose of the buffer. Animals with a blood glucose level higher than $300 \mathrm{mg} / \mathrm{dl}, 3$ days after streptozotocin injection, were used in the experiment [10]. Diabetic rats in groups III and IV were treated with a daily subcutaneous injection of insulin glargine (Lantus, $100 \mathrm{IU} / \mathrm{ml}$; Sanofi Aventis, Frankfurt, Germany). The dose of insulin was $3 \mathrm{IU} / \mathrm{day} / \mathrm{rat}$, in 2 divided doses for 8 weeks. The dose of insulin was adjusted to maintain the life of animals (not to return blood glucose to normal) [6]. At the end of the 
experiment, blood glucose levels were measured using Ascensia contour blood glucose monitoring system (Bayer Health Care, Berkshire, UK).

Determination of serum C-peptide levels: At the end of experiment, blood samples from each rat were collected into appropriately-labeled sterile tubes and allowed to clot, then left for 10 minutes at room temperature for serum formation. The tubes were centrifuged at $3750 \mathrm{~g}$ for 5 minutes. The sera were collected in appropriately-labeled tubes, kept frozen at $-20^{\circ} \mathrm{C}$, and then used for determination of C-peptide levels. Serum C-peptide concentrations were measured by radioimmunoassay according to the manufacturer's instructions (Rat C-Peptide RIA KIT, Cat. \# RCP-21K; Millipore, St. Charles, Missouri, USA).

Statistical Analysis: Data collected were subjected to statistical analysis using SPSS (PASW Statistics 18) software, where analysis of variance (ANOVA) was used for an overall comparison between the study groups, and the post hoc Tukey HSD test was used for pair wise comparisons. Differences were considered significant when $\mathrm{p}$ was less than or equal to 0.05 .

\section{RESULTS:}

The mean fasting blood glucose level was significantly higher $(p<0.05)$ in rats of groups III (insulin-treated diabetic group) and IV (date seed extract-insulin-treated diabetic group) when comparing each of them to those in groups I (control group) and II (date seed extract-treated control group). The mean fasting blood glucose level was significantly lower in group IV when compared to that in group III $(p<0.05)$. No significant difference in mean fasting blood glucose levels was found between rats of groups I and II ( $p>0.05)$ (Fig. 1).

Figure 1. Blood glucose levels (mean $\pm \mathrm{SD})(\mathrm{mg} / \mathrm{dl})$ in all studied groups

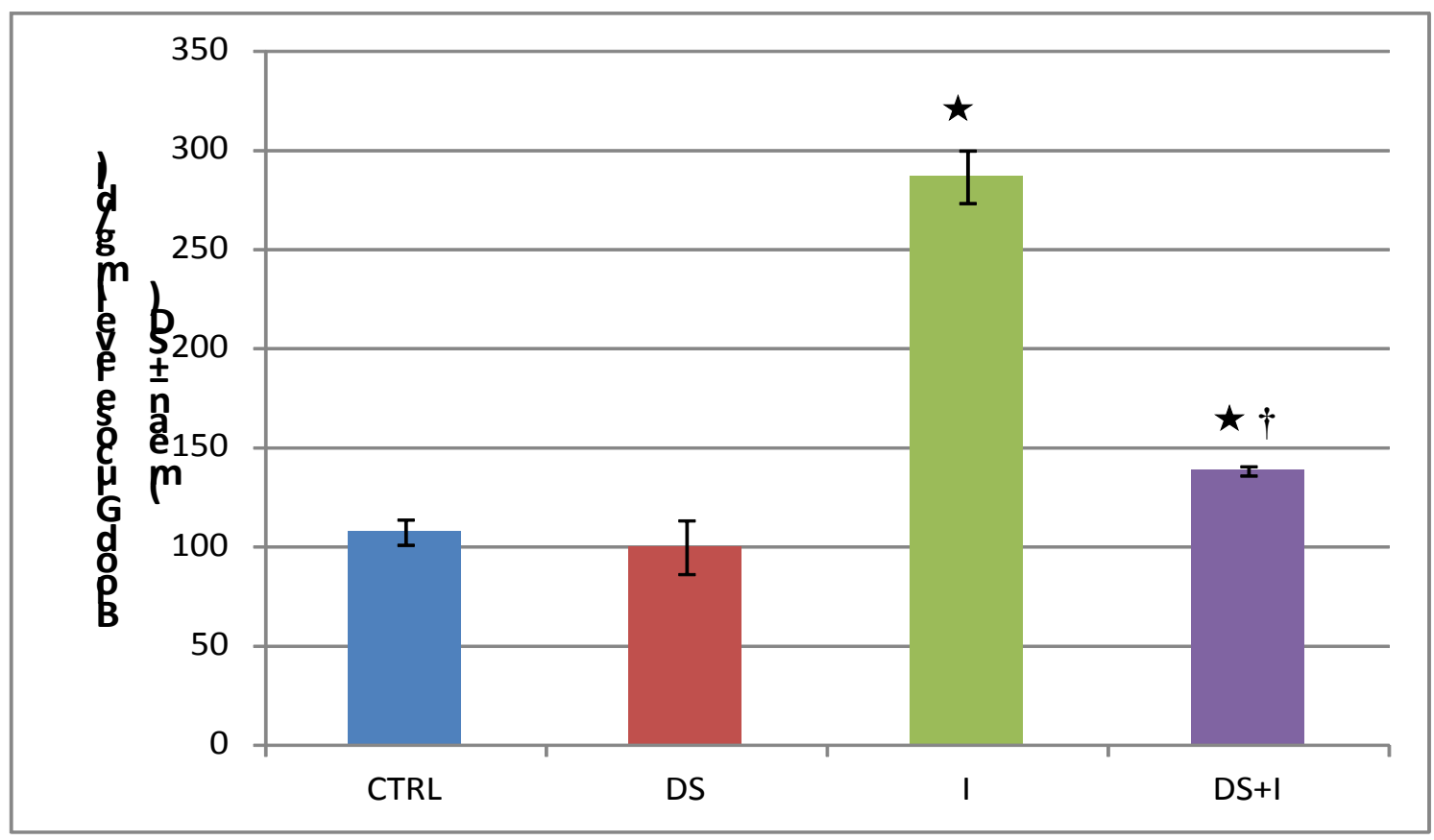

Significant difference compared to groups I \& II.

$\uparrow$ Significant difference compared to group III.

CTRL = Control; DS = Date seed I = Insulin; DS + I = Date seed + Insulin 
No significant differences $(p>0.05)$ in mean serum C-peptide level were observed between groups I and II. Groups III and IV showed a statistically significant reduction in serum C-peptide level $(p<0.05)$ compared to groups I and II. The mean serum C-peptide level was significantly higher in group IV compared to group III ( $p<0.05)$ (Fig. 2).

Figure 2. Serum C-peptide levels (mean $\pm \mathrm{SD}$ ) $(\mathrm{pM})$ in all studied groups

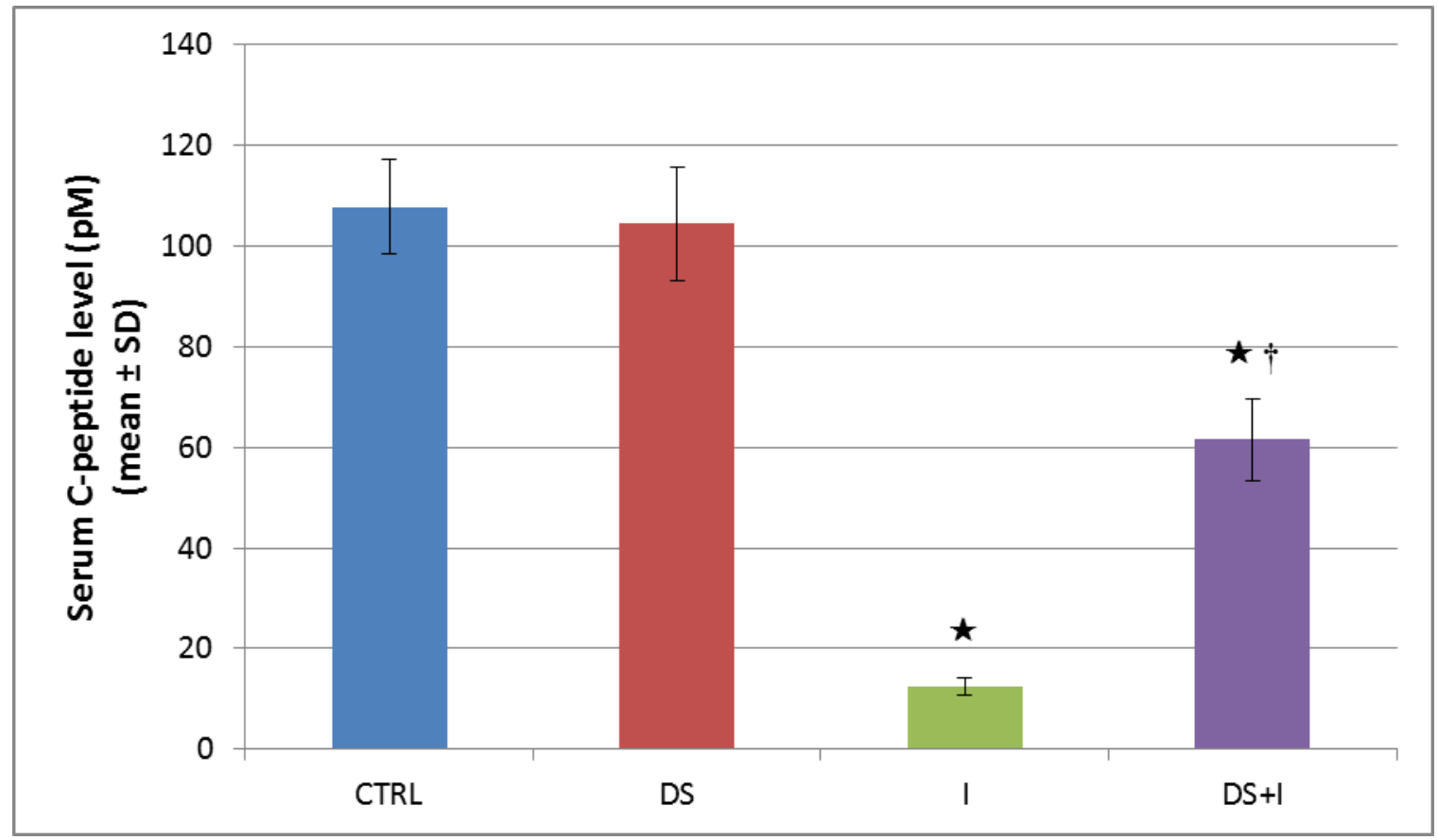

Significant difference compared to groups I \& II.

$\dagger$ Significant difference compared to group III.

CTRL = Control; DS = Date seed; I = Insulin; DS + I = Date seed + Insulin

\section{DISCUSSION:}

The efficacy of an aqueous extract from date seeds has been tested successfully on the glycemic control of T1DM in rats [6]. The mean blood glucose levels were found to be significantly lower in diabetic rats treated with the date seed extract-insulin combination compared to insulin-treated diabetic rats. The safety of date seed extract administration on liver and kidney of rats was also demonstrated. In addition, the date seed extract-insulin combination was found to minimize the toxic effects of diabetes on these organs [7]. The previous results stimulated the authors to conduct the present study, aiming to investigate the potential mechanism by which date seed extract exerts its hypoglycemic effect.

A biochemical study was performed to measure the serum C-peptide levels in rats of control and diabetic groups. Evaluation of C-peptide level is a useful parameter to indicate the amount of endogenous insulin secreted in the body [11]. No significant differences in mean serum C-peptide levels were observed between control groups (group I and II). The results obtained after the measurement of serum C-peptide levels were in accordance with those obtained after measurement of blood glucose levels in which no significant differences in mean 
blood glucose levels were detected between the control groups. Both results indicated the absence of a hypoglycemic effect for the date seed extract when administered to normoglycemic animals. The serum blood glucose levels were significantly low, while the serum C-peptide levels were significantly high in date seed extract-insulin-treated diabetic rats (group IV) when compared to those obtained in insulin-treated diabetic rats (group III). Biochemical results suggested an increase in endogenous insulin secretion in case of diabetic rats treated with date seed extract, which might be the cause of its hypoglycemic effect, and subsequently to the significant reduction of mean blood glucose level in such rats, compared to those treated with insulin as a single drug. The effect of date seed extract on the control of hyperglycemia is further supported by our previous report [7], indicating that the combination of date seed extract and insulin minimizes the histopathological effects of diabetes on liver and kidney of diabetic rats when compared to insulin administration for the same period.

The results of the present study would stimulate the conduction of an immunohistochemical study on the insulin-secreting cells (Beta cells) of the pancreatic islets of diabetic rats treated with date seed extract. Also, the present results would encourage further studies to investigate the effect of dosage variation and the duration of the administration of the date seed extract on type I diabetic rats.

\section{CONCLUSIONS:}

Date seed extract has a hypoglycemic effect on type 1 diabetic rats. Date seed extract causes an increase in endogenous insulin secretion, which might be the cause of its hypoglycemic effect.

\section{Competing interests:}

The authors declare that there is no conflict of interest.

\section{Authors' contribution:}

All authors contributed to this study.

\section{Acknowledgements and funding:}

The authors acknowledge the Research Center, college of Medicine, King Saud University, Riyadh, KSA for the financial support and continuous encouragement.

\section{REFERENCES:}

1. Dahlquist G, Kallen B. Mortality in childhood-onset type 1 diabetes: a populationbased study. Diabetes Care 2005; 28: 2384-2387.

2. CDC. 2011 national diabetes fact sheet: national estimates and general information on diabetes and prediabetes in the United States 2011 Atlanta, GA: US Department of Health and Human Services, CDC. Available from http://www.cdc.gov/diabetes/pubs/factsheet11.htm. accessed October 29, 2012.

3. Van den Berghe G. How does blood glucose control with insulin save lives in intensive care? J Clin Invest 2004; 114: 1187-1195. 
4. Peyrot M, Rubin RR, Kruger DE, Travis LB. Correlates of insulin injection omission. Diabetes Care 2010; 33: 240-245.

5. Payne C. Complementary and integrative medicine: emerging therapies for diabetes. Part I. Diabetes spectrum 2001; 14: 129-131.

6. El Fouhil AF, Ahmed AM, Darwish HH. Hypoglycemic effect of an extract from date seeds on diabetic rats. Saudi Med J 2010; 31(7): 747-751.

7. El Fouhil AF, Ahmed AM, Darwish HH, Atteya M, Al-Roalle AH. An extract from date seeds having a hypoglycemic effect. Is it safe to use? Saudi Med J 2011; 32(8): 791-796.

8. Wahren J, Ekberg K, Jörnvall H. C-peptide is a bioactive peptide. Diabetologia 2007; 50 (3): 503-509.

9. Egleton RD, Campos CC, Huber JD, Brown RC, Davis TP. Differential effects of diabetes on rat choroid plexus ion transporter expression. Diabetes 2003; 52(6): 14961501.

10. Gad HI.The potential osteogenic effects of systemic leptin and insulin administration in streptozotocin-induced diabetic female rats. Saudi Med J 2007; 28: 1185-1190.

11. Marques RG, Fontaine MJ, Rogers J. C-peptide: much more than a byproduct of insulin biosynthesis. Pancreas 2004; 29 (3): 231-238. 